\title{
A história do presente em Foucault \\ E AS LUTAS ATUAIS
}

\author{
Kleber Prado Filho ${ }^{I, \star}$; Lilia Ferreira Lobo ${ }^{I I}$; Flávia Cristina Silveira Lemos ${ }^{I I I}$ \\ ${ }^{I}$ Universidade Federal de Santa Catarina, Florianópolis, SC, Brasil \\ ${ }^{I I}$ Universidade Federal Fluminense, Niterói, RJ, Brasil \\ III Universidade Federal do Pará, Belém, PA, Brasil
}

\section{Resumo}

Este artigo promove um debate sobre as lutas sociais e politicas a partir das pesquisas de Michel Foucault, em uma história do presente, apontando contribuições das análises de arquivos e de ferramentas que nos inquietam pela força do questionamento que produzem e também pela atitude crítica e política que possibilitam, bem como a postura ética que movem nos trabalhos em psicologia social, no Brasil. O legado de Foucault é vasto pela potência de seus escritos e rupturas provocadas em diferentes áreas entre pesquisadores e militantes, em muitos países, o que diz de suas ressonâncias e da importância de escrever a respeito.

Palavras-chave: Foucault; história; pesquisa; lutas atuais; crítica.

\section{The history OF THIS IN FOUCAULT AND THE CURRENT STRUGGLES}

\begin{abstract}
s
This paper promotes a discussion of the social and political struggles from the research of Michel Foucault, in a history of this, pointing contributions analyzes of files and tools that unsettle us by force of questioning that produce and also by the critical attitude and enabling policy and the ethical stance that move us work in social psychology in Brazil. Foucault's legacy is the vast power of his writings and disruptions caused in different areas between researchers and activists in many countries, which says its resonances and the importance of writing about it.
\end{abstract}

Keywords: Foucault; history; research; current struggles; criticism.

\footnotetext{
^Endereço para correspondência: Universidade Federal de Santa Catarina, Centro de Filosofia e Ciências Humanas, Departamento de Psicologia. Campus Universitário - Trindade. 88040-970 Florianopolis, SC - Brasil - Caixa-postal: 5068.

E-mail:kleberprado.psi@gmail.com, lilialobo@yahoo.com.br, flavazevedo@bol.com.br
} 
Foucault foi um dos filósofos que mais valorizou o ato de pesquisar tanto que este termo encontra-se sempre presente em seus escritos, sejam cursos, artigos, entrevistas, livros, uma vasta obra caracterizada por um trabalho febril de pesquisa.

Em seu curso de 1975-1976 Em defesa da sociedade (FOUCAULT, 1999), na primeira aula de janeiro, menciona, salvo, 13 vezes esse termo pesquisa. Pesquisar está principalmente de forma inequívoca e em ato, na prática de investigação - a grande tarefa de um filósofo-artesão, cujo ofício é forjar as armas de combate às repetições do presente. Cada curso que ele ministrava era fruto de um ano de pesquisa em tempo integral, conforme contrato de trabalho no Collège de France.

E, com as ferramentas que inventou para a história, construiu todo o seu pensamento filosófico - a genealogia - termo que extraiu da obra de Nietzsche $A$ genealogia da moral (FOUCAULT, 1979). Desde sua primeira grande obra, História da loucura na Idade Clássica, em 1961, já se pode encontrar, mesmo não explicitamente, uma arqueologia e uma genealogia, cujas práticas de dizibilidade e visibilidade viriam a ser enunciadas em seus livros posteriores.

É preciso deixar claro que tais formas jamais se constituíram em uma teoria, mas por precauções metodológicas em relação aos conceitos universais e/ou universalizantes (FOUCAULT, 1988), em recomendações estratégicas, na busca de desmontagem de objetos prévios tão indispensáveis à construção teórica. Sendo assim, a genealogia torna efetivo o desrespeito pelos recortes históricos consagrados, libertando o curso da história das amarras das sequências das continuidades, dos invariantes, das representações e das tentativas de explicação dialética.

A descontinuidade é para a genealogia uma ferramenta de pesquisa, a ferramenta que faz irromper as diferenças nas permanências do mesmo. "A descontinuidade era o estigma da dispersão temporal que o historiador se encarregava de suprimir da história" (FOUCAULT, 1986, p. 10). A pesquisa genealógica é uma investigação. Quem nos fala a esse respeito é Jacques Donzelot (1979) em um texto intitulado "The poverty of political culture", onde apresenta alguns argumentos para contrastar as perspectivas de pesquisa no campo das representações e da genealogia. A primeira teria mais afinidade com o teatro por causa do status que atribui à realidade, separando esta da aparência. Descrever a realidade das representações seria supor a existência de um real verdadeiro ofuscado pelo senso comum das representações, das ideologias de classe, gênero ou, enfim, pelas forças produtivas introduzidas como análise de causalidade.

Por outro lado, a genealogia estaria mais próxima dos gêneros literários menores, das histórias de detetives. Não há nada a buscar por detrás das aparências, a não ser traços; indícios de passagens cujos fios tornam possível investigar os enigmas dos processos que vêm nos constituindo tal como somos no presente e que estamos em vias de ser na atualidade. Investigar indícios, não é o mesmo que procurar causas. A realidade para a genealogia é um invisível não escondido, um modo de apresentação, uma referência a ser iluminada ou tornada visível pela constituição de uma superfície de inscrições, através da ligação dos indícios de passagens (como as pegadas) e não de relações simbólicas a serem interpretadas em suas causas profundas, escondidas ou recalcadas. 
O genealogista terá que esculpir esses rastros, traçados nos documentos, em séries, em séries de séries, transformando-os em monumentos, "esses rastros deixados pelos homens", tantos quantos puderem ser "isolados, agrupados, tornados pertinentes, inter-relacionados, organizados em conjuntos" (FOUCAULT, 1986, p. 08). Como então escolher num emaranhado de ocorrências aquilo que se quer surpreender?

Seguir suas trilhas, as linhas de transformação é nunca estacionar nas formas dos estratos sociais (as instituições, por exemplo), é jamais tomá-las em si, mesmo quando se considera o contexto de relações com outras formas, mas entender os agenciamentos (DELEUZE, 1992), as relações de força, os dispositivos de poder que as instituíram como tal. É seguir pistas como nas histórias de detetive, fragmentos que poderão engendrar muitas outras genealogias. Por isso, investigar documentos é mais do que simplesmente seguir pegadas que, certamente, foram deixadas em um tempo passado.

Apenas uma prática teórica, enquanto produção de verdades instrumentaliza certas manipulações conforme o alvo a atingir. Como na arte da caça um caçador que espreita sua caça, rastreia suas pegadas, estuda seu comportamento, suas rotinas, todos os seus sinais e só então prepara a armadilha e se coloca no melhor lugar para surpreendê-la, ou quem sabe, ser surpreendido por ela e obrigar-se, então, a remontar suas estratégias; assim também, como na arte da caça, nenhuma teleologia orienta a pesquisa genealógica.

Trabalhar o passado, seguir a trilha das antigas proveniências e articular pontos de emergência das atuais formações é pretender a crítica do presente; dos mecanismos normalizadores que por extensão se deslocam por toda a sociedade. Não para dar conta da totalidade dos controles da vida social, mas para desmontar-lhes mais uma peça. (LOBO, 2008). Uma caçada implica também na exploração do terreno da constituição histórica de sujeitos, de uma ontologia histórica das subjetivações, de uma análise não linear que aborde uma emergência de práticas e a construção de discursos, a discussão das questões políticas que os engendraram e que possam ser confrontadas com o que ocorre na atualidade.

$\mathrm{Na}$ base da emergência de novos objetos está a pesquisa das descontinuidades. A propósito, Paul Veyne (1998, p. 172) apresenta uma figura interessante para clarificar a passagem descontínua do tempo histórico. Embora minuciosa, a pesquisa genealógica é fragmentária porque recusa qualquer pretensão de totalidade. Não se trata, portanto, da proposta um método geral, prescritivo, válido em definitivo, capaz de validar pela simples aplicação as verdades que supõe descobrir. Por desprezar tanto quanto possível as generalizações totalizadoras, a pesquisa precisa colocar-se no pequeno lugar de funcionamento onde a prática engendra o objeto, outro rigor aí se enuncia.

A pesquisa então partirá das práticas discursivas e não discursivas e, para isso elas precisam ser verificadas e verificáveis. Uma enorme massa do material de pesquisa, entre todo o tipo de documentos, Foucault disponibilizou em seus livros, submetendo-os à refutação por parte dos historiadores. No lugar da demonstração a experiência. A esse respeito, Foucault (apud ERIBON, 1996, p. 40) é um 
filósofos que valorizou a experiência em suas pesquisas e, surpreendentemente, a manteve no plano pessoal: "Cada vez que tentei fazer um trabalho teórico, foi a partir de minha própria experiência, sempre em relação com processos que eu via se desenrolarem em torno de mim".

Uma inquietação que, embora pessoal ou autobiográfica, como apelidava sua obra, nunca foi centrada num eu subjetivo, porque realizou a incrível façanha de torná-la instrumento de seu trabalho de pesquisa. Uma experimentação que demandava a sensibilidade de afecções transformadoras de um "si mesmo" voltadas para fora, sendo um autor que escreve para deixar de ser, para desaparecer e surpreender-se consigo mesmo. Um pensamento estratégico como este "implica certas escolhas metodológicas", dentre as quais, como afirma Michel Foucault, "um ceticismo sistemático acerca dos universais antropológicos. Isto não quer dizer que se deva rejeitá-los todos desde o começo, de uma vez para sempre, mas que não se deva aceitar nada desta ordem que não seja estritamente indispensável". (FOUCAULT, 1988, p. 14).

Uma interrogação crítica sobre nós mesmos era o projeto de estudos que encantava Foucault, que ele denominou "ontologia histórica de nós mesmos", um trabalho ético, político e filosófico como experimentação cotidiana que pode se desdobrar em pesquisas diversas, no sentido de "promover novas formas de subjetividade através da recusa deste tipo de individualidade que nos foi imposto há vários séculos" (FOUCAULT, 1995, p. 239). Por fim, Foucault (2005, p. 342) nos sugere para a pesquisa não propriamente um método, mas um ethos, no sentido grego desta palavra, uma atitude, termo que ele propõe quando discute os textos de Kant sobre o Iluminismo: "uma maneira de pensar e de sentir, uma maneira também de agir e de se conduzir que, tudo ao mesmo tempo, marca uma pertinência e se apresenta como uma tarefa".

Um caminho ético, não uma prescrição ou uma doutrina, mas um caminho extremamente rigoroso. Preciosa contribuição para a pesquisa em psicologia social ao insistir nas relações de força presentes nas práticas cotidianas que forjam os modos de subjetivação contemporâneos, os combates do presente que compõem a "ontologia histórica de nós mesmos". Distanciando-se da perspectiva que norteia as pesquisas no âmbito social como representações sobre um objeto dado, Foucault (2010, p. 04) propõe o conceito de pensamento como análise do que ele denomina como "focos de experiência":

nos quais se articulam uns sobre os outros: primeiro, as formas de um saber possível; segundo, as matrizes normativas de comportamento para os indivíduos e enfim os modos de existência virtuais para sujeitos possíveis. Esses três elementos de um saber possível, matrizes normativas de comportamento, modos de existência virtuais para sujeitos possíveis - [...] é a articulação dessas três coisas que podemos chamar de focos de experiência. 
Pensamento como focos de experiência capazes de produzir verdades, de inventar modos de ser. Como Foucault é um filósofo dedicado às questões da verdade, à pluralidade de sentidos da verdade, a um desses sentidos dedicou toda a sua obra: àquele que supõe um risco político das experiências limite (EWALD, 2004), o risco da parresia (parrhèsia), o risco de falar a verdade, um ethos que demanda a coragem de enfrentar o perigo, de interromper as repetições do presente: "É que o saber não é feito para compreender, ele é feito para cortar" (FOUCAULT, 1979. p. 28). Eis a indicação foucaultiana de um projeto para a psicologia social.

Essa reflexão será atravessada por alguns conceitos que, mais que meros recursos teóricos, operam como instrumentos metodológicos, no sentido dos usos da "caixa de ferramentas" preconizada por Nietzsche e Foucault. A caixa de ferramentas é uma figura metodológica utilizada para ambos como uma maneira de ressaltar o caráter instrumental e político de uma aplicação metodológica, destacando sua dimensão operativa, somada à estratégica e ao que tange a mobilidade no emprego de diferentes técnicas conforme cada situação ou problema enfrentado.

O conteúdo da caixa de ferramentas é um conjunto díspar de instrumentos metodológicos críticos, estrategicamente utilizados para desmontar mitos, conceitos, enunciados, discursos, teorias, mas também, objetos concretos, práticas, dispositivos, situações, contextos históricos, modos de vida e de ser.

Outro conceito desta caixa é o de problematização, pois permite colocar em questão como e porque um tema emerge em determinado momento como problema a ser equacionado tanto teórica quanto praticamente por certa sociedade, destacando o caráter histórico e político da formação de "vontades de verdade" na cultura ocidental. Uma problematização pode referir-se ainda à estratégia metodológica singular empregada na construção e articulação de uma questão de pesquisa.

A noção de experiência também era relevante na medida em que possibilitou descentrar um sentido de vivência subjetiva, individual referido a um campo de relações, acontecimentos e práticas coletivas, históricas, anônimas e impessoais, onde o sujeito não é causa nem origem e sim, consequência. Assim, definir experiência como acontecimento implica em enfatizar o caráter descontínuo, intempestivo, muitas vezes acidental da história, que não se escreve a partir da postulação de uma origem e de marcos históricos, encadeando um desenvolvimento progressivo posto em termos de fases, etapas ou períodos, cumprindo um percurso teleológico, e sim, através da leitura dos acontecimentos, que não são necessariamente grandes, nem evidentes. Um acontecimento pode assinalar a descontinuidade de um fluxo, a ruptura de um processo, de uma experiência ou de uma prática, como pode ainda possibilitar emergências diversas: a irrupção da diferença, de um ato transgressivo, uma prática de resistência ou de liberdade - é nesse registro que um acontecimento deve ser lido. 


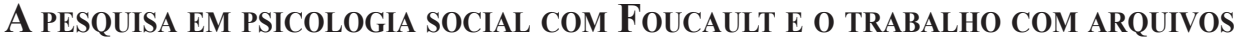

O trabalho com documentos e as ofensivas éticas e políticas, na atualidade, conforme Foucault (2005, p. 72) chegou a afirmar eram o seu objeto e preocupação de trabalho nas pesquisas documentais, em arquivos; assim, ele declara que: "[...] meu objeto não é a linguagem, mas o arquivo, ou seja, a existência acumulada de discursos".

"Analisar os fatos de discurso no elemento geral de arquivo é considerá-los não absolutamente como documentos (de uma significação escondida ou de uma regra de construção), mas como monumentos (FOUCAULT, 2005, p. 95). Na introdução do curso Em defesa da sociedade, Foucault (1999, p. 07) relata como estava acometido por uma:

[...] preguiça febril, a que afeta o caráter dos que adoram as bibliotecas, os documentos, as referências, as escrituras empoeiradas, os textos que jamais são lidos, os livros que, mal são impressos, são fechados de novo e dormem depois em prateleiras das quais só são tirados alguns séculos mais tarde.

$\mathrm{O}$ arquivo pressupõe o arquivista; uma mão que coleciona e classifica. [...] (p. 11) O arquivo não é uma nota; não foi composto para surpreender, agradar ou informar, mas para servir a uma polícia [...]. (p. 14). Talvez o arquivo não diga a verdade, mas ele diz da verdade, tal qual entendia Michel Foucault. [...] (p. 35) Michel Foucault foi um desses encontros, simples e ao mesmo tempo desconcertante. Ele amava o manuscrito e ao arquivo, e chegou a descrever como esses textos de poucos recursos o impressionavam. (FARGE, 2009, p. 11-36).

O trabalho com documentos poderia ter, assim, uma dimensão de luta constituída como uma agonística, tal qual pensada por Foucault (2004) em suas análises da produção das práticas de resistência. Para este autor, não há um sujeito possuidor da liberdade fundamental enquanto uma essência, mas sim o exercício de práticas produtoras de campos de possíveis, de lutas que abririam espaços de liberdade sempre provisórios. Contudo, Foucault (1979) também não negou que existiria um conjunto de lutas capturadas em dispositivos de dominação mais globais e amplos, como: racismo, procedimentos de coerção e de situações de violência, estigmas em função da idade e da classe social, preconceitos de gênero e de etnia entre outros. Por isto, ele afirma que as lutas são transversais (FOUCAULT, 1995).

Geralmente, pode-se dizer que existem três tipos de lutas: contra as formas de dominação: étnica, social e religiosa; contra as formas de exploração que separam os indivíduos daquilo que eles produzem; ou contra aquilo que liga o indivíduo a si mesmo e o submete, deste modo, aos outros (lutas contra a sujeição, contra as formas de subjetivação e submissão). Acredito que na história podemos encontrar 
muitos exemplos destes três tipos de lutas sociais, isoladas umas das outras ou misturadas entre si. [...] E, atualmente, a luta contra as formas de sujeição - contra a submissão da subjetividade - está se tornando cada vez mais importante, a despeito de as lutas contra as formas de dominação e exploração não terem desaparecido. Muito pelo contrário. [...] Sem dúvidas, os mecanismos de sujeição não podem ser estudados fora de sua relação com os mecanismos de exploração e dominação. (FOUCAULT, 1995, p. 235-236).

Uma relação de violência age sobre um corpo, sobre as coisas; ela força, ela submete, ela quebra, ela destrói; ela fecha todas as possibilidades; não tem, portanto, junto de si, outro polo senão aquele da passividade; e, se encontra uma resistência, a única escolha é tentar reduzi-la. (FOUCAULT, 2004, p. 243).

Todavia, Foucault (2004) diferencia as relações de poder dos procedimentos de coerção e violência. A violência e a coerção não são relações de poder para ele e sim uma relação em que alguém está completamente à disposição do outro, à mercê enquanto objeto de outrem. A relação de poder só ocorre onde há possibilidade de resistência, de liberdade e de contrapoder.

Se há relações de poder em todo o campo social, é porque há liberdade por todo lado. Mas há efetivamente estados de dominação. Em inúmeros casos, as relações de poder estão de tal forma fixadas que se tornam perpetuamente desiguais, sendo a margem de liberdade extremamente limitada (FOUCAULT, 2004, p. 277).

Politizar estas questões e trazê-las como objeto de pesquisa tem toda uma implicação ética e de emergência de análises de acontecimentos que estavam silenciados e impedidos de circular como parte de uma memória a ser escrita e narrada por uma multiplicidade de vozes e não apenas por um prisma prescritivo e institucional apenas.

De minha parte, procuro mostrar e analisar a relação que existe entre um conjunto de técnicas de poder e de formas [...]. O problema ao qual Goffman se prende é o da instituição mesma. O meu é o da racionalização da gestão do indivíduo. Meu trabalho não tem como objetivo uma história das instituições ou uma história das ideias, mas a história da racionalidade, tal como ela opera nas instituições e na conduta das pessoas (2006a, p. 319).

Se eu estudei práticas como as do sequestro dos loucos, ou da medicina clínica, ou da organização da das ciências empíricas, ou da punição legal, foi para estudar um jogo entre um código que regula maneiras da fazer (que prescreve como selecionar as pessoas, como educar os indivíduos etc) 
e uma produção de discursos verdadeiros que servem de fundamento, de justificação, de razões de ser e princípio de transformações a essas mesmas maneiras de fazer. Para dizer as coisas claramente: meu problema é saber como os homens se governam (eles próprios e os outros) através da produção da verdade (FOUCAULT, 2006b, 342-343).

“O exercício do poder não é simplesmente uma relação entre parceiros individuais e coletivos; é um modo de ação de alguns sobre outros (Foucault, 1995, p. 242)". Tratava-se de efetuar uma história problema: [...] em que o verdadeiro exercício crítico do pensamento se opõe à ideia de uma busca metódica da solução: a tarefa da filosofia não é resolver - incluindo a substituir de uma solução por outra -, mas problematizar; não é reformar, mas instaurar uma distância crítica (REVEL, 2004, p. 82).

Assim, Foucault (2006c, p. 339) enfatiza que faz uma história das práticas datadas e raras, dispersas, acontecimentais e não das instituições ou das ideologias, procurando trabalhar com uma:

[...] acontecimentalização [...], uma ruptura [...], trata-se de fazer surgir uma singularidade. [...] consiste em reencontrar as conexões, os encontros, os apoios, os bloqueios, os jogos de força, as estratégias etc., que, em um dado momento, formaram o que, em seguida, funcionará como evidência, universalidade, necessidade. [...] Uma espécie de desmultiplicação causal. [...] Analisar o acontecimento segundo os processos múltiplos que o constituem [...].

A forma como o problema é colocado implica em efetuar determinadas respostas. Problematizar é pensar práticas, analisando acontecimentos singulares em um enfrentamento permanente, como um jogo em cada batalha e que, então, seria a marca dos embates entre os corpos que buscam romper com processos de assujeitamento. "É que o saber não é feito para compreender, ele é feito para cortar" (FOUCAULT, 1979).

O trabalho do genealogista é demorar-se sobre os documentos como monumentos que narram o cotidiano, os detalhes banais, o que parece não ter história. Trata-se de uma "constituição de um saber histórico das lutas e a utilização deste saber nas táticas atuais" (FOUCAULT, 1979, p. 171). Para colocar em deslocamento a verdade como ciência, que já implica em efeitos de poder, Foucault passou a utilizar o termo saber e a criticar a noção de conhecimento. Estes saberes estão em dispersão e entrecortados em séries, ou seja, o corte acontece quando as séries vão se tornando distintas, operando em níveis diagonais móveis.

A genealogia é cinza; ela é pacientemente documentária. Ela trabalha com pergaminhos embaralhados, riscados, várias vezes reescritos. [...] Daí, para a genealogia, um 
indispensável demorar-se: marcar as singularidades dos acontecimentos, longe de toda finalidade monótona; espreitá-los lá onde menos se os esperava e naquilo que é tido como não possuindo história - os sentimentos, o amor, a consciência, os instintos. [...] (FOUCAULT, 1979, p. 15)

Neste projeto genealógico, as relações de poder passam a ser analisadas por Foucault, na genealogia por meio de postulados, como: o da propriedade, em que o poder é uma relação estratégica mais do que uma propriedade; o da localização que viu o Estado como o lugar do poder ou ainda a instituição, mas este lugar é interrogado por ser composto por multiplicidades de forças; no postulado da subordinação inquieta a tentativa de colocar uma relação como causa ou dependência de outra; o postulado do atributo está ligado à divisão entre dominantes e dominados, entretanto, para Foucault o poder é uma relação e opera sempre sem se fixar a um grupo específico; outro postulado é o da modalidade em que se define poder como repressivo e violência ou ideologia, no entanto, poder é ação sobre ação para incitar, compor e investir, normalizar e suscitar; no postulado da legalidade, o Estado age pela lei que coage e proíbe, mas, Foucault ressalta que a relação de poder é uma prática que é estratégia e tática mais do que lei. Assim, que o diagrama se diferencia do arquivo porque é um mapa móvel e co-extensivo ao campo social, mistura matérias fluidas, imanentes e em devir (DELEUZE, 1992).

\section{FORMAS CONTEMPORÂNEAS DE LUTA SOCIAL: TRANSVERSALIDADE,} RESISTÊNCIA E PRÁTICAS DE LIBERDADE NA PESQUISA EM PSICOLOGIA SOCIAL

O século XIX nos deixa como legado duas grandes matrizes de crítica social: uma ligada a Marx, que fez escola fundando a tradição marxista e outra, ligada a Nietzsche, que não se constitui como ortodoxia, formando aquilo que tem sido denominado "desconstrução nietzschiana", que passa no início do século XX por Heidegger e, mais contemporaneamente, por Foucault, Deleuze e Guattari. A tradição marxista, inspirada no combativo pensamento de Marx, foi, ao longo da segunda metade do século XIX e primeira metade do XX, a grande inspiradora de revoltas sociais ocorridos no período, resultando em uma diversidade de revoluções em várias regiões do planeta, envolvendo enfrentamentos de cunho político e econômico contra o Estado e o Capital.

A revolução de caráter marxista foi grande modelo de luta social adotado no período, que acabou resultando em algumas radicais "tomadas do poder", a exemplo da Revolução Soviética de 1917 e a Revolução Cubana de 1959, envolvendo um enfrentamento verticalizado da estrutura social, composta pelas massas trabalhadoras, mobilizadas contra as superestruturas políticas, jurídicas, produtivas e ideológicas burguesas.

A cartilha desse modelo é o texto "Manifesto comunista" e seu arquiteto foi Lênin, considerado o grande articulador do projeto revolucionário marxista-leninista de desmontagem e superação do capitalismo internacional, visando à ocupação estratégica do aparelho de Estado para implantar uma ditadura do proletariado consoante com uma sociedade socialista, onde a propriedade dos 
meios de produção seja coletiva. Na passagem dos anos 1920 aos 1930, num contexto de ascensão do fascismo na Itália, Antonio Gramsci rompendo com a ortodoxia revolucionária marxista-leninista, transfere o foco da luta social da estrutura para a superestrutura, ficando por isso conhecido na discursividade marxista como "o teórico das superestruturas".

Nesse movimento ele remete o problema da revolução ao campo da cultura, aos confrontos ideológicos entre classes, em disputa por um predomínio capaz de construir uma hegemonia que garanta uma ligação orgânica entre estrutura e superestrutura, formando um bloco histórico. Essa ruptura com a ortodoxia marxista dá nascimento àquilo que veio a ser denominado "marxismo ocidental", onde Gramsci ocupa o posto de "filósofo da práxis".

Práxis implica fusão e imbricação entre teoria e prática, entre ideologia e ação política, exigindo que a prática revolucionária tenha consistente sustentação teórica, o que dá destaque ao papel exercido pelos intelectuais num processo revolucionário, de condução e direção ideológica. No entanto, partir da década de 1960, esses modos de luta passam a ser questionados por não darem conta da complexidade e capilaridade dos confrontos políticos concretos à época, sendo o episódio do "Maio de 1968" o grande indicador dessa tendência. O que está em questão ali não é a dominação pelo Estado, nem a opressão capitalista, mas as pequenas vigilâncias e sujeições cotidianas.

Não se trata ali de uma revolução, mas de uma agitação anárquica, sem direção ou condução; nem se trata ali de um embate ideológico, mas de uma libertação da palavra e dos corpos, dando mostras daquilo que Foucault denomina: "uma rebelião das condutas". Este acontecimento político dá visibilidade a outras formas de luta deslocadas desses modelos verticalizados, apontando para a transversalidade dos enfrentamentos sociais.

Uma luta transversal, diferentemente de uma revolução verticalizada contra o Estado ou o Capital, mobiliza-se tematicamente em torno de questões estratégicas diversas, não se limita a fronteiras nacionais, além de ser um tipo de enfrentamento mais imediato e específico, contra instâncias de poder mais próximas dos sujeitos. Talvez, o exemplo mais significativo dessa modalidade de luta entre nós seja a recusa aos jogos de verdade da norma em torno de questões diversas em nossa cultura, levando a embates cotidianos concretos contra práticas de sexualização e marcação da identidade sexual, e contra práticas de patologização e normalização do campo da saúde mental, que implicam na marcação da identidade do louco como doente mental e na nomeação da sua loucura.

Os enfrentamentos em torno da afirmação do direito à diversidade sexual recusa do império da heteronormatividade no campo da sexualidade - e a luta antimanicomial, contra a norma psiquiátrica da saúde mental, são exemplos marcantes dessa modalidade de confronto social. Lutas transversais implicam enfrentamento e desmontagem de dispositivos normalizantes, subjetivantes e individualizantes! 
Conforme Foucault (1995), há três tipos de luta política: contra formas de dominação, contra formas de exploração econômica e aquelas que se mobilizam anarquicamente contra formas históricas de sujeição e assujeitamento que ligam o sujeito a si mesmo e aos outros; envolvendo jogos de individualização e identificação, correlatos de modos de objetivação e subjetivação. São lutas que questionam o estatuto do indivíduo e se voltam contra certo pastorado das condutas cotidianas ou um governo pela individualização. Nas suas próprias palavras:

Talvez, o objetivo hoje em dia não seja descobrir o que somos, mas recusar o que somos. Temos que imaginar e construir o que poderíamos ser para nos livrarmos desse "duplo constrangimento" político, que é a simultânea individualização e totalização própria às estruturas do poder moderno. A conclusão seria que o problema político, ético, social e filosófico de nossos dias não consiste em tentar liberar o indivíduo do Estado nem das instituições do Estado, oporem nos liberarmos tanto do Estado quanto do tipo de individualização que a ele se liga. Temos que promover novas formas de subjetividade através da recusa deste tipo de individualidade que nos foi imposta há vários séculos. (FOUCAULT, 1995, p. 239).

Portanto, o que está em questão aqui não é a condução ou hegemonia de um movimento revolucionário contra o Estado ou o Capital, mas o agenciamento de práticas de resistência e de liberdade contra técnicas de produção de subjetividade e formas de governo da individualidade, envolvendo centralmente uma recusa daquilo que somos hoje e do que estamos em via de deixar de ser.

As práticas de resistência e de liberdade são elementos fundamentais da genealogia do poder e da ética de Michel Foucault, diretamente ligados à capilaridade e transversalidade dos enfrentamentos sociais cotidianos, que envolvem produção concreta de corpos e subjetividades. Esses diferentes tipos de luta envolvem modalidades diversas de atividade e postura política, o que leva à fundamental questão colocada por cada uma dessas perspectivas, em diferentes momentos: quem ou qual é o agente revolucionário, transformador das relações sociais, ou ainda, posto de outra forma, que lugar ocuparia o intelectual nessas modalidades de enfrentamento?

Na verdade, são diferentes estatutos de intelectual em cada um desses tipos de luta. No modelo marxista-leninista temos a figura do "intelectual engajado", do ativista revolucionário lutando, de armas em punho, contra a opressão e exploração do Capital, pela tomada do aparelho de Estado burguês. Na tradição do marxismo ocidental temos a figura do "intelectual orgânico" - cimento do bloco histórico - como articulador ideológico, agente da luta ideológica, desmontando a ideologia dominante, afirmando uma ideologia proletária, com isso conferindo organicidade ao bloco histórico. 
A figura correlata das lutas transversais é o intelectual específico, tema tratado em uma entrevista concedida por Foucault (2003) a Deleuze em 1972, publicada com o título: "Os intelectuais e o poder". Este intelectual nada tem a ver com o intelectual escritor, teórico, nem ocupa-se de questões universais, totalizantes e abstratas, mas volta-se para a singularidade dos acontecimentos, investe numa problematização de práticas e jogos de verdade, lançando um olhar crítico sobre o nosso mundo e àquilo que somos, visando traçar uma história do presente. $\mathrm{O}$ intelectual específico ocupa ainda importante lugar nas insurreições de grupos, em termos de agenciamento e articulação das forças desse coletivo.

O exercício de crítica possibilitaria resistências e a criação de zonas de liberdade, em uma batalha permanente, em que a pesquisa e a escrita seriam armas de guerra, em uma ontologia histórica de nós mesmos (FOUCAULT, 1984). Na intercessão com Foucault, queremos produzir curto-circuito, como ele dizia que desejava fazer, nos apropriando da genealogia como uma arma de luta para dispersar tudo que parece cristalizado e definido, questionando racionalidades disciplinares e biopolíticas que foram instituídas em programas de gestão da vida e materializadas em dispositivos e engrenagens políticas sustentadas por regimes de verdade.

[...] Paul Veyne faz um retrato de Foucault como guerreiro. Foucault sempre invoca a poeira ou o murmúrio de um combate, e o próprio pensamento lhe aparece como uma máquina de guerra. É que, no momento em que alguém dá um passo fora do que já foi pensado, quando se aventura para fora do reconhecível e do tranqüilizador, quando precisa inventar novos conceitos para terras desconhecidas, caem os métodos e as morais, e pensar torna-se, como diz Foucault, um "ato arriscado", uma violência que se exerce primeiro sobre si mesmo. [...] (DELEUZE, 1992, 128).

A atitude crítica que possibilita questionar a forma como esse governo atua, abrindo espaço para pensar "como não ser governado assim, em nome desses princípios, em vista de tais objetivos e por meio de tais procedimentos, não dessa forma, não para isso, não por eles" (FOUCAULT, 2005, p. 03).

A atitude crítica, entendida como "indocilidade refletida", é assim utilizada como força motriz para o desassujeitamento no jogo da política da verdade. Analisando os dispositivos de poder-saber, Foucault (1979) propôs por meio da pesquisa documental uma postura crítica das condições de possibilidades de emergência dos acontecimentos, utilizando ferramentas de uma história belicosa para efetuar seu trabalho.

Desse modo, produziu relevantes instrumentos de análise, como o método genealógico, visando problematizar as práticas sociais com uma preocupação política, em que fabricava uma história política da verdade. Tais lutas são entendidas como propostas pelo autor como um movimento de recusa de quem somos (FOUCAULT, 1995) e servem para questionar o estatuto do indivíduo, possibilitando a promoção de novas formas de subjetividade, outros modos de ser e, consequentemente, outras formas de intervenção em questões tidas como problemáticas. 
As pesquisas históricas de Foucault são cartografias, mapas, diagramas que operam uma história problematizadora, que produz um pensar interrogante e estabelecido no espanto, no estranhamento, em um exercício constante de demolição das evidências.

Finalizando, a história do presente é uma modalidade de análise praticada por Foucault que consiste no emprego da história como recurso para criticar o presente, expondo sua estratégia de utilizar a história como método para o exercício filosófico. A história do presente possibilita em última instância a crítica e recusa daquilo que somos: nossa subjetividade, nossos modos de vida e de ser, nossas relações, nosso mundo.

\section{REFERÊNCIAS}

DELEUZE, G. Conversações. Rio de Janeiro: Editora 34, 1992.

DONZELOT, J. The poverty of political culture. Ideology and Consciousness, [S.1.], n. 5, p. 73-86, 1979.

ERIBON, D. Michel Foucault e seus contemporâneos. Rio de Janeiro: J. Zahar, 1996.

EWALD, F. La philosophie comme act. Le Magazine Littéraire: Dossier Michel Foucault, n. 435, p. 30-31, oct. 2004.

FARGE, A. O sabor do arquivo. São Paulo: EDUSP, 2009.

FOUCAULT, M. Microfisica do poder. Rio de Janeiro, Graal, 1979.

FOUCAULT, M. Nietzsche, Freud, Marx: Theatrum Philosoficum. 5. ed. São Paulo: Princípio, 1984.

FOUCAULT, M. Arqueologia do Saber. Rio de Janeiro: Forense Universitária, 1986.

FOUCAULT, M. (Auto)biography - 1926- 84. In: . History of present. San Francisco: University of Califórnia, 1988. p. 13-15.

FOUCAULT, M. O sujeito e o poder. In: DREYFUS, H.; RABINOW, P. (Org.). Michel Foucault, uma trajetória filosófica: para além do estruturalismo e da hermenêutica. Rio de Janeiro: Forense/Universitária, 1995, p. 231-249.

FOUCAULT, M. História da loucura na Idade Clássica (1961). 5. ed. São Paulo: Perspectiva, 1997.

FOUCAULT, M. Em defesa da sociedade. São Paulo: Martins Fontes, 1999. 
FOUCAULT, M. Os intelectuais e o poder. In: MOTTA, M. B. da (Org.). Estratégia, poder-saber.Rio de Janeiro: Forense/Universitária, 2003. Coleção Ditos \& Escritos, v. 4, p. 37-47.

FOUCAULT, M. O cuidado com a verdade. In: MOTTA, M. B. da (Org.). Ética, sexualidade, política. Rio de Janeiro: Forense Universitária, 2004. Coleção Ditos \& Escritos, v. 5, p. 240-251.

FOUCAULT, M. O que são as Luzes. In: MOTTA, M. B. da (Org.). Arqueologia das ciências e história dos sistemas de pensamento. Rio de Janeiro: Forense Universitária, 2005. Coleção Ditos \& Escritos, v. 2, p. 335-351.

FOUCAULT, M. Foucault estuda a razão de Estado. In: MOTTA, M. B. da. (Org.). Michel Foucault: estratégia, poder-saber. 2. ed. Rio de janeiro: Forense Universitária, 2006a. Coleção Ditos \& Escritos, v. 4, p. 319-322.

FOUCAULT, M. Mesa redonda em 20 de maio de 1978. In: MOTTA, M. B. da. (Org.). Michel Foucault: estratégia, poder-saber. 2. ed. Rio de janeiro, Forense Universitária, 2006b. Coleção Ditos \& Escritos, v. 4, p. 335-351.

FOUCAULT, M. Poder e saber. In: MOTTA, M. B. da (Org.). Estratégia, podersaber. 2. ed. Rio de Janeiro: Forense Universitária, 2006c. Coleção Ditos \& Escritos, v. 4, p. 223-240.

FOUCAULT, M. O governo de si e dos outros. São Paulo: WMF Martins Fontes, 2010.

LOBO, L. F. Os infames da história: pobres, escravos e deficientes no Brasil. Rio de Janeiro: Lamparina/FAPERJ, 2008.

REVEL, J. Foucault: conceitos essenciais. São Carlos/SP: Claraluz, 2005.

VEYNE, P. Foucault revoluciona a história. In: . Como se escreve a história. Brasília: UNB, 1998. p. 239-285.

Recebido em: 02 de maio de 2012 Aceito em: 14 de setembro de 2012 